\title{
The cardiopulmonary bypass and cancer dissemination puzzle ${ }^{1}$
}

Paulo Roberto Barbosa Évora', Agnes Afrodite Sumarelli Albuquerque", Tales Rubens de Nadai"', Enio David Mente ${ }^{\mathrm{IV}}$, Ajith Kumar Sankarankuty ${ }^{\mathrm{IV}}$, Orlando Castro-e-Silvav

'PhD, Full Professor, Division of Thoracic and Cardiovascular Surgery, Department of Surgery and Anatomy, Faculdade de Medicina de Ribeirão Preto - Universidade de São Paulo (FMRP-USP), Ribeirao Preto-SP, Brazil. Conception and design of the study, manuscript writing, critical revision.

"Fellow Master degree, Experimental Medicine Program, Division of Thoracic and Cardiovascular Surgery, Department of Surgery and Anatomy, FMRP-USP, Ribeirao Preto-SP, Brazil. Acquisition of data.

I'Fellow PhD degree, Experimental Medicine Program, Division of Thoracic and Cardiovascular Surgery, Department of Surgery and Anatomy, FMRP-USP, Ribeirao Preto-SP, Brazil. Acquisition of data.

IVPhD, Assistant Professor, Department of Surgery and Anatomy, Division of Digestive Surgery, FMRP-USP, Ribeirao PretoSP, Brazil. Acquisition of data.

${ }^{\vee}$ Full Professor, Surgery and Anatomy Department, FMRP-USP, Ribeirao Preto-SP, and Department of Gastroenterology, Medical School, USP, Sao Paulo-SP, Brazil. Critical revision.

\section{Abstract}

Early cancer diagnosis, new therapies that increased survival of patients, besides the increasingly elderly population are some factors would be associated with possible cancer dissemination in patients under cardiopulmonary bypass (CPB) cardiac surgery. Also, the benefits, and risks, regarding long-term survival, have not yet been established. Therefore, cardiac surgery morbimortality may be superior in patients with cancer disease. Also, immunologic and inflammatory changes secondary to CPB can also increase tumor recurrence. After a brief introduction and CPB immunologic the two main topic subjects included: 1) Combined heart surgery and lung resection and; 2) Possible influence of neoplasia type. After observing the relative literature scarcity, we keep the opinion that "CPB has a modest association with cancer progression" and that "CPB and cancer dissemination should be a logical but unlikely association."

Key words: Cardiopulmonary Bypass. Thoracic Surgery. 


\section{- Introduction}

Early cancer diagnosis, new therapies that increased survival of patients, besides the increasingly elderly population are some factors would be associated with possible cancer dissemination in patients under cardiopulmonary bypass (CPB) cardiac surgery. Also, the benefits, and risks, regarding longterm survival, have not yet been established. Therefore, cardiac surgery morbimortality may be superior in patients with cancer disease. Also, immunologic and inflammatory changes secondary to CPB can also increase tumor recurrence ${ }^{1}$.

We published recent editorial emphasizing that some CPB aspects of immune suppression and cancer dissemination still yet to be determined ${ }^{2}$. Published reported results to show a non-statistically significant increase in the risk of cancer-specific mortality before any diagnosis of cancer. Also, there is no significant increase in the case-fatality rate for those cancer patients who underwent CPB surgery before the cancer diagnosis. Also, cancer stage at the time of diagnosis, have no impact on the relative risk of mortality. These concepts inspired the editorial title "Cardiopulmonary bypass and cancer dissemination: A logical but unlikely association," which define the problem rationale and motivation review ${ }^{2}$.

Based on these observations we intend to review the controversial and enigmatic of the cause/effect regarding the association between cancer dissemination and CPB. Discussing particularities of oncology and inflammatory reaction escapes the scope of the review. The review rationale is presented in Figure 1 and the "learning remarks" are presented in Table 1.

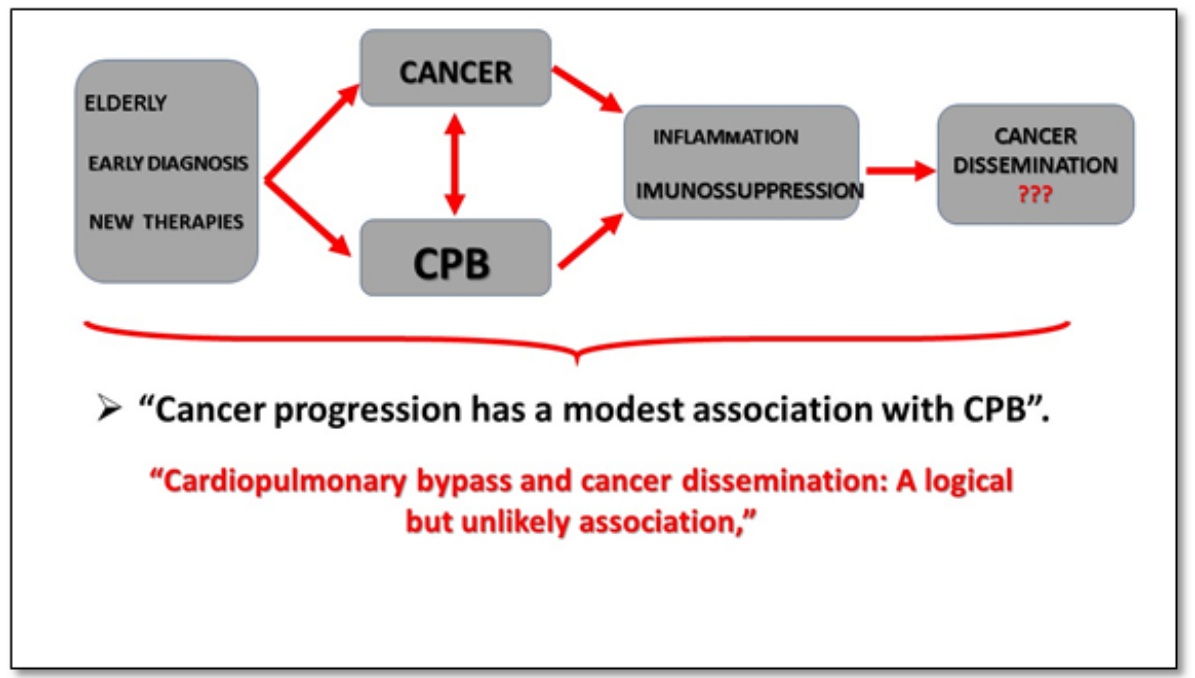

Figure 1 - Rationale graphical presentation. 
Table 1 - Learning remarks.

1. Increasingly elderly population, early cancer diagnosis and new therapies that increased survival of patients with malignancies. Since both cardiac disease and malignancy are widely prevalent, it is not infrequent to see patients facing both active cardiac disease and malignancy at the same time.

2. Inflammatory phenomena and immunologic changes secondary to CPB can increase tumor recurrence. There are two possible mechanisms through which CPB might contribute to the hematogenous dissemination of tumor cells. First, tumor cells contaminated in the reservoir blood might spread through the arterial cannula. Second, modification of homeostasis by CPB may liberate tumor cells to which has been suppressed by the host defense system.

3. Cancer progression has a modest association with CPB.

4. Usually, patients who need cardiac intervention 10 years or more after cancer treatment have survival equivalent to age-matched non-cancer patients.

5. In some reports, hematological malignancies should not be considered a contraindication for cardiac CPB surgery.

6. Cardiac surgery using CPB did not have a negative impact on the natural course of chronic lymphatic leukemia (CLL).

7. Cardiac disease management in active cancer patients is sophisticated and requires a multi-disciplinary approach, with input from cardiology, cardiothoracic surgery, and oncology.

\section{General immunologic and oncologic aspects}

According to Hasegawa et al. ${ }^{3}$, application CPB to oncologic patients is still controversial with the possible disadvantages of hematogenous dissemination of tumor cells. These authors refer to two possible mechanisms through which CPB might contribute to the hematogenous dissemination of tumor cells. First, tumor cells contaminated in the reservoir blood might spread through the arterial cannula. Second, the CPB homeostasis imbalance may contribute to neoplasia cells dissemination preoperatively suppressed by the host defense system.

\section{- Possible influence of neoplasia type}

We did not find any publications directly correlating the type of neoplasia with possible dissemination caused or favored by cardiopulmonary bypass. In other words, it can not be said that a particular type of cancer is more susceptible to dissemination by CPB.

Suzuki et al. ${ }^{4}$ studied seventy-four cancer patients who underwent cardiac surgery before cancer therapy were followed up for $42 \pm 37$ months; 45 had cardiac surgery with CPB.

Pinto et $a .^{5}$ carried out the first population-based multicenter cohort study in patients with underlying cardiovascular disease and no pre-existing cancer diagnosis which used robust propensity score modeling to adjust for baseline imbalances and which accounted for competing risks. They conclude that further research may still be warranted to assess whether the transient immunosuppression associated with CPB can promote the spread and growth of pre-existing cancer cells. These authors emphasize the need for a particular focus on skin melanoma and lung cancer which had the most significant association in this study. 
Plumereau et $a .^{6}$ following the best evidence topic in cardiac surgery addressed the question whether patients with hematological malignancy (HM) who need (CPB) have higher short-term mortality or a higher chance of disease progression secondary to CPB. Altogether, 107 papers were found using the reported search terms, but ultimately only eight were relevant to our subject. They found four case series and four case-control series. Most of the found papers were only short series. The final evaluation emphasized the study limitations linked to the low-evidence levels in some of the papers used but concluded that hematological malignancies should not be considered a contraindication for cardiac CPB surgery.

In some reports, hematological malignancies should not be considered a contraindication for cardiac CPB surgery. Cardiac surgery using CPB did not have a negative impact on the natural course of chronic lymphatic leukemia (CLL). Although it may be an early postoperative risk factor, it is not a contraindication for cardiac surgery using $\mathrm{CPB}^{7}$.

As an overview, the literature data suggest that CPB has a modest association with cancer progression. Patients who need cardiac intervention 10 years or more after cancer treatment, usually have survival equivalent to age-matched noncancer patients.

About the combined operation for lung cancer and cardiac disease, the Mayo Clinic experience concluded that although pulmonary resection for lung cancer in patients undergoing simultaneous open heart operation can be performed safely with low morbidity and mortality, long-term survival may be compromised. Candidates for the combined procedures should be limited to patients who cannot tolerate a second procedure?.

Finally, as an overview, the literature data suggest that CPB has a modest association with cancer progression. Patients who need cardiac intervention 10 years or more after cancer treatment, usually have survival equivalent to age-matched noncancer patients. Reinforcing this modest association, it is worth remembering that the initial concern of developing special CPB circuits and filters has lost importance over time.

\section{- Combined heart surgery and lung resection}

This issue remains controversial but deserves a brief note since they are intrathoracic structures. The surgical procedures have been staged, performing the cardiac surgery before the pulmonary resection at a later date. The management of patients with resectable lung tumors and coexisting cardiac disease is subject to debate as the operative mortality for lung resection in such patients is increased. However, exists criticism related to the possible CPB effects on malignancy, proper extent of lung resection from the non-standard approach and higher risk of bleeding. According to Santavy et al. ${ }^{10}$ based on 10 patients, combined treatment of cardiac disease and lung cancer is a feasible and safe method with excellent results. It can be carried out with acceptable morbidity and mortality. The off-pump revascularization should be a good idea in the attempt to minimize blood loss and theoretical CPBinduced tumor dissemination ${ }^{8,9}$.

The Table 2 shows the seven references that were freely chosen for the elaboration of ideas about the influence of CPB in patients with cancer. 
Table 2. The seven references that were freely chosen for the elaboration of ideas about the influence of CPB in patients with cancer.

- Suzuki et al (2010) studied seventy-four cancer patients who underwent cardiac surgery before cancer therapy were followed up for $42 \pm 37$ months; 45 had cardiac surgery with CPB. Asian Cardiovasc Thorac Ann. 2010 Dec; 18(6):536-40

- Pinto CA (2013). An increased risk for overall cancer incidence $(17 \%)$ and cancer-specific mortality ( $16 \%$ overall, $12 \%$ case fatality) was observed; without statistical significance. Cancer. 2013;13:519

- Plumereau F, et al (2014) found four case series and four case-control series concluding that hematological malignancies should not be considered a contraindication for cardiac CPB surgery. Interact Cardiovasc Thorac Surg. 2014 Sep; 19(3):474-8

- Miller DLet al (1994) From 1965 through 1992, evaluated 30 patients (23 men and 7 women) underwent pulmonary resection for primary lung cancer and a concomitant open-heart operation, concluding that resection for lung cancer in patients undergoing concomitant open heart operation can be performed safely with low morbidity and mortality, long-term survival may be compromised. Ann Thorac Surg. 1994 Oct; 58(4):989-93;.

- Danton MH et al. Simultaneous pulmonary resection and cardiac surgery in thirteen patients was associated with acceptable operative morbidity and mortality. Eur J Cardiothorac Surg. 1998 Jun;13(6):667-72.

- Cathenis K, et al. Performed a retrospective review of 27 patients who underwent pulmonary and cardiac surgery, from 2000 to 2008, concluding that simultaneous procedures for cardiac disease and pulmonary lesions can be performed without life-threatening morbidity and no in-hospital mortality. Acta Chir Belg. 2009 May-Jun; 109(3):306-11.

- Šantavý P ete al (2015) based on ten patients, combined treatment of cardiac disease and lung cancer is a feasible and safe method with excellent results. Cor et Vasa April 2015; 57(2):e82-e85

\section{Conclusions}

The cardiac disease should be mainly prevalent, especially in prostate and lung cancer patients, breast cancer patients and patients who underwent chest irradiation for any cause. Secondary prevention mostly revolves around controlling risk factors, such as hypertension, diabetes and smoking cessation, statin and aspirin therapy also showed benefit. Management of cardiac disease in active cancer patients is sophisticated and requires a multi-disciplinary approach, with input from cardiology, cardiothoracic surgery, and oncology.
Generally, the more aggressive approach is preferred when cancer is curable or long-term survivorship is expected, while the conservative approach is used when the cancer is widespread and incurable. Cardiac disease (coronary, valvular, or myocardial) is common in cancer survivors, and successful interventions have been reported, but at increased incidence of preoperative morbidity.

\section{References}

1. Carrascal Y, Gualis J, Arévalo A, Fulquet E, Flórez S, Rey J, Echevarría JR, Di Stefano S, Fiz L. Cardiac surgery with extracorporeal circulation in cancer patients: influence 
on surgical morbidity and mortality and survival. Rev Esp Cardiol. 2008;61(4):36975. PMID: 18405517.

2. Braile DM, Évora PRB. Cardiopulmonary bypass and cancer dissemination: a logical but unlikely association. Braz J Cardiovasc Surg. 2018;33(1):I-II. PMID: 29617496.

3. Hasegawa S, Otake Y, Bando T, Cho H, Inui K, Wada $\mathrm{H}$. Pulmonary dissemination of tumor cells after extended resection of thyroid carcinoma with cardiopulmonary bypass. J Thorac Cardiovasc Surg. 2002;124(3):635-6. PMID: 12202885.

4. Suzuki S, Usui A, Yoshida K, Matsuura A, Ichihara T, Ueda Y. Effect of cardiopulmonary bypass on cancer prognosis. Asian Cardiovasc Thorac Ann. 2010;18(6):536-40. PMID: 21149401.

5. Pinto CA, Marcella S, August DA, Holland B, Kostis JB, Demissie K. Cardiopulmonary bypass has a modest association with cancer progression: a retrospective cohort study. BMC Cancer. 2013;13:519. PMID: 24180710.

6. Plumereau F, Pinaud F, Roch A, Baufreton C. Do patients with hematological malignancy who need cardiopulmonary bypass have short-term higher mortality or a higher chance of disease progression? Interact Cardiovasc Thorac Surg. 2014;19(3):474-8. PMID: 24920761.

7. Miller DL, Orszulak TA, Pairolero PC, Trastek VF, Schaff HV. Combined operation for lung cancer and cardiac disease. Ann Thorac Surg. 1994;58(4):989-93; discussion 993-4. PMID: 7944820.

8. Danton $\mathrm{MH}$, Anikin VA, McManus KG, McGuigan JA, Campalani G. Simultaneous cardiac surgery with pulmonary resection: presentation of series and review of literature. Eur J Cardiothorac Surg. 1998;13(6):667-72. PMID: 9686798.

9. Cathenis K, Hamerlijnck R, Vermassen F, Van Nooten G, Muysoms F. Concomitant cardiac surgery and pulmonary resection. Acta Chir Belg. 2009;109(3):306-11. PMID: 19943584. 10.Šantavý P, Szkorupa M, TomasBohanes T, Lonský V. Simultaneous cardiac surgery with pulmonary resection. Cor et Vasa. 2015;57(2):e82-e85. doi: 10.1016/j. crvasa.2015.02.007.

\section{Correspondence:}

Prof. Dr. Paulo Roberto Barbosa Évora Hospital das Clínicas de Ribeirão Preto, Departamento de Cirurgia e Anatomia Avenida Bandeirantes 3900, Campus Universitário 14049-900 Ribeirão Preto - SP Brasil Tel.: (55 16)3602-2593 prbevora@fmrp.usp.br

Received: July 03, 2018 Review: Sept 06, 2018 Accepted: Oct 09, 2018
Conflict of interest: none

Financial sources: FAPESP, CAPES, and CNPq
${ }^{1}$ Research performed at Department of Surgery and Anatomy, Faculdade de Medicina de Ribeirao Preto, Universidade de São Paulo (FMRP-USP), Ribeirao Preto-SP, Brazil. 